\title{
Farklı Zamanlarda Yapılan Yaprak Alma ve Uç Alma Uygulamalarının Üzümde Salkım Özellikleri Üzerine Etkilerinin Belirlenmesi
}

\author{
ilknur KORKUTAL ${ }^{* 1}$ (D) Elman BAHAR ${ }^{1}$ (D) Arzu ZINNi ${ }^{2}$ \\ ${ }^{1}$ Tekirdağ Namık Kemal Üniversitesi Ziraat Fakültesi Bahçe Bitkileri Bölümü 59030 Tekirdağ \\ 2 TÜRAM Tarım Lisesi, Gümüşyaka Merkez Mahallesi, 34580 Silivri - Istanbul
}

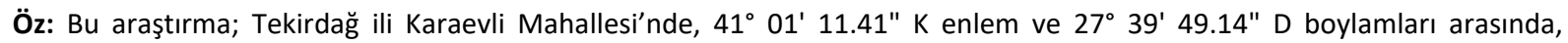
bulunan Reşat Koşar'a ait bağda yetiştiriciliği yapılan, Michele Palieri/110R aşı kombinasyonundan oluşan, omcalar üzerinde yaprak alma ve uç alma uygulamalarının, salkım özelikleri ve verim özellikleri üzerine etkilerinin belirlenmesi amacıyla yürütülmüştür. Deneme 2018-2019 ve 2019-2020 vejetasyon periyotlarında iki yıl süreyle yürütülmüştür. Denemede 3 uygulama zamanı (Tane Tutumu, İri Koruk, Ben Düşme) ve 4 farklı [Kontrol, Yaprak Alma Yok-Uç Alma Var (YAY-UA), Yaprak Alma Var-Uç Alma Yok (YA-UAY) ve Yaprak Alma Var-Uç Alma Var (YA-UA)] uygulama bulunmaktadır. Araştırmaya fenolojik gözlemlerle başlanmış, salkım özellikleri ve verim özellikleri incelenmiş ve verim özellikleri belirlenmiştir. Sonuç olarak; salkım özelliklerini ve verim özelliklerini iyileştirmek için İri Koruk ve Ben Düşme döneminde YA-UA uygulaması önerilmiştir.

Anahtar kelimeler: Michele Palieri, Yaprak Alma, Uç Alma, Sofralık Üzüm

Determination the Effects of Leaf Removal and Topping at Different Times on the Grape Cluster

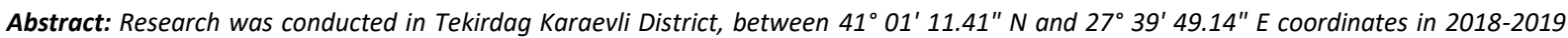
and 2019-2020 periods Michele Palieri/110R grafting combination was used as a plant material in vigneron Reşat Koşar's vineyard. The aim of research was determination of the effects of topping and leaf removal on cluster characteristics, yield characteristics were examined. The were 3 different application periods [Berry Set (BS), Bunch Closure (BC), Veraison (V)] and 4 different applications [Control (C), No Leaf Removal-Topping (NLR-T), Leaf Removal-No Topping (LR-NT), Leaf Removal-Topping (LR-T)] in the research. In the beginning of research phenological stages were recorded. Cluster characteristics, yield characteristics were examined. As a result; $L R-T$ application in the BC and $V$ period to positive effect on the cluster properties and yield properties is proposed.

Keywords: Michele Palieri, Leaf Removal, Topping, Table Grape

GiRiş

Omcaların gelişiminde üretim merkezi-tüketim merkezi dengesi öncelikle kış budamaları, devamında da yeşil budama uygulamaları ile kurulmaya çalışılır (Vivin ve ark., 2002; Mota ve ark., 2010). Uç alma, sürgün ucunun 7-15 cm'lik kısmının alınması; yaprak alma işlemi yaşlı, gölge yapan ve havalandırmayı engelleyen yaprakların alınmasıdır (Çelik, 2017; Teker, 2017; Yüksel ve Ateş, 2020). Yaprak alma, salkım bölgesindeki mikroklimanın ve üzüm kompozisyonunun düzenlemesini sağlayan bir uygulamadır (Mosetti ve ark., 2016). Ayrıca verimi de olumlu yönde etkilemektedir (Vogel ve ark., 2020). Uç alma sürgünün büyümesini kısıtlama amacıyla otsu kısmın alınması olarak da tanımlanabilir (Hernandes ve Junior, 2018).

Köse ve ark. (2018), Trakya illkeren üzüm çeşidinde salkım ağırlığı ve salkım boyunun; 10 gün arayla 7 kez ve ortalama 2 adet yaprak alınarak arttığını belirlemişlerdir. Kaya (2019), Karaerik üzüm çeşidine çiçeklenme öncesi, tam çiçeklenme ve tane tutumunda yaprak alma uygulamış; sonuç olarak kontrole kıyasla salkım eni-boyu ve salkım ağırlığının arttığı, verim ve salkım sıklığının da azaldığını görmüştür. Merlot, Cabernet-Sauvignon ve Sangiovese üzüm çeşitlerine tane tutumunda 3 farklı şiddette yaprak alma uygulaması yapılmıştır. Yaprak alma omca başına düşen verimi ve salkım ağırlığını Merlot ve Sangiovese üzüm çeşitlerinde azaltmıştır. Salkım sıklığı sadece Merlot üzüm çeşidinde yaprak alma şiddetine bağı olarak azalmıştır. CabernetSauvignon üzüm çeşidinde kontrollü yaprak alma ile verimde bir değişiklik meydana gelmemiştir (Kotseridis ve ark., 2012). Cabernet-Sauvignon üzüm çeşidinde yapılan ana yaprak alma uygulamasının; salkım ağırlığı, salkım hacmi ile salkımdaki tane sayısı değerlerini yükselttiği belirlenmiştir (Bahar ve Öner, 2015). Syrah üzüm çeşidinde ana yaprakların asma üzerinde bırakıldığı uygulamanın verimi azalttığı ve salkım iriliğini arttırdığı belirlenmiştir (Korkutal ve ark., 2017). Ayrıca Sauvignon Blanc çeşidinde altı farklı dönemde yapılan yaprak alma uygulamalarından; en yüksek verim değerine eriştiren dönemlerin tanelerin bezelye iriliğinde ve ben düşmede olduğu aşamalar olarak saptanmıştır (Würz ve ark., 2018). Üç farklı seviyede tepe alma gerçekleştirilen Yalova Çekirdeksizi/5BB aşı kombinasyonuna sahip omcalarda yapılan farklı uygulamaların ortalama verimde önemli bir değişikliği yol açmadığı ortaya konmuştur (Dardeniz ve ark., 2018). Benzer şekilde Red Globe üzüm çeşidinde 3 farklı fenolojik aşamada gerçekleştirilen yaprak alma uygulamasının salkım

*Sorumlu Yazar: ikorkutal@nku.edu.tr

Geliş Tarihi: 07 Aralık 2020

Kabul Tarihi: 10 Aralık 2021 
eni, salkım boyu ve verim üzerinde fark oluşturmadığı belirlenmiştir (Kılıç, 2019). Merlot/5BB aşı kombinasyonuna sahip omcalara 4 farklı dönemde uç alma yapılmış ve tane tutumu döneminde yapılan uç alma ile salkım özelliklerinin istenilen seviyeye eriştiği kaydedilmiştir (Korkutal ve ark., 2018).

Bu çalışmanın amacı farklı zamanlarda Michele Palieri üzüm çeşidinde yapılan yaprak alma ve uç alma uygulamalarının üzümde salkım özellikleri üzerine etkilerinin belirlenmesidir.

\section{MATERYAL VE YÖNTEM}

\section{Materyal}

Araştırma, Trakya Bölgesi (Tekirdağ ili Karaevli Köyü) koşullarında, 110R (Berlandieri Resseguier No. 2 x Vitis rupestris cv. Martin) anacı üzerine aşılı Michele Palieri (Alphonse Lavallée $x$ Red Malaga) üzüm çeşidinin yer aldığı 10 yaşındaki omcalarda 2018-2019 ve 2019-2020 yılları vejetasyon periyodunda 2 yıl süreyle yürütülmüştür. Bağ alanında 2.5 × $1.5 \mathrm{~m}$ sıra arası ve sıra üzeri mesafede dikilmiş olan omcalara T şekli verilmiştir ve $170 \mathrm{~cm}$ gövde yüksekliğine sahiptir. Sürgünler $90-140 \mathrm{~cm}$ olduğu dönemde sürgün (30-40 sürgün) ve salkım sayıları (20-30 salkım) dengelenmiştir.

Bağda vejetasyon periyodu boyunca; çapalama, sıra arası ot biçme işlemleri gerçekleştirilmiştir. Kış mevsiminde toprak işleme öncesinde taban gübresi verilmiştir. Damlama ile gübre desteği gözler uyanmadan çiçek öncesi ve tanelerin ben düşme olgunlaşma dönemine kadar N, P, K gübreleri ile birlikte; besin elementi eksikliğine göre yapraktan ekstra gübreleme yapılmıştır. Yapraklar döküldükten sonra ve gözler kabardığında bordo bulamacı, gözler uyanıp sürgünler $15-20 \mathrm{~cm}$ uzunluğuna geldiğinde ölü kol ve sürgün-tane gelişimi boyunca mildiyö ilaçları kullanılmıştır. Tane tutumundan sonra da külleme, ben düşmeden itibaren de salkım güvesi ile Botrytis sp. ilaçlaması gerçekleştirilmiştir. Sulama sadece gübreleri (damla sulama) vermek için kullanılmış, bunun dışında bitki su ihtiyacı yağmurlarla karşılanmıştır.

\section{Yöntem}

Denemede; Tane Tutumu (TT), İri Koruk (IK) ve Ben Düşme (BD) olmak üzere üç farklı dönemde; dört farklı yaprak ve uç alma kombinasyonları: Yaprak Alma Yok-Uç Alma Yok (Kontrol), Yaprak Alma Yok-Uç Alma (YAY-UA), Yaprak AlmaUç Alma Yok (YA-UAY), Yaprak Alma-Uç Alma (YA-UA) uygulanmıştır. Uç alma; son salkımdan itibaren 8-10 yaprak bırakılıp üstte kalan kısmının alınması şeklinde yapılmıştır. Aynı zamanda uç alma işlemi sırasında koltuk sürgünlerindeki yaprak sayısı da (3 adet) düşürülmüştür. Yaprak alma ise: dipten ilk dört yaprağın alınması şeklinde gerçekleştirilmiştir. Farklı yaprak alma ve uç alma uygulamaların salkım özellikleri üzerine etkilerini ortaya koymak için; hasat sırasında her uygulamadan alınan beş 158 adet salkımda; salkım eni $(\mathrm{cm})$, salkım boyu $(\mathrm{cm})$, salkım ağırlı̆ı (g), salkım hacmi $\left(\mathrm{cm}^{3}\right)$, salkımdaki tane sayısı (adet), salkım sıklığı [Salkım sıklığı=Salkım hacmi $\left(\mathrm{cm}^{3}\right) /($ Salkımdaki tane sayısı $x$ tane hacmi $\left.\left(\mathrm{cm}^{3}\right)\right]$ (OIV, 2009) ve verim özelliklerini belirlemek için omca başına verim (kg/omca), birinci sınıf salkım oranı (\%), ikinci sınıf salkım oranı (\%) kriterleri incelenmiştir. Ayrıca fenolojik gelişim tarihleri Lorenz ve ark. (1995)'na göre Tekirdağ Meteoroloji Müdürlüğü’nden (TMM, 2019) alınan veriler doğrultusunda kaydedilmiştir. Tesadüf Blokları Deneme Deseninde kurulan araştırmada; 3 tekerrür ve her tekerrürde 2 omca olmak üzere toplam 72 omca kullanılmıştır. Elde edilen sonuçlar MSTAT-C ve JUMP istatistik paket programları ile değerlendirilmiş ve uygulamalar arasındaki farklılıklar LSD testi ile belirlenmiştir.

\section{BULGULAR VE TARTIŞMA}

\section{Tekirdağ iline Ait İklim Verilerine Göre Belirlenen Fenolojik} Gelişme Tarihleri

Araştırma süresince deneme alanına ait 2018 ve 2019 yıllarındaki bazı iklim verileri Tekirdağ ili Süleymanpaşa Meteoroloji İstasyonu'ndan elde edilmiştir. Tekirdağ'da yetiştirilen Michele Palieri üzüm çeşidi omcalarında 2018 yılında Tane Tutumu (EL 27) 06 Haziran'da, İri Koruk (EL 31) 26 Haziran'da ve Ben Düşme (EL 35) 25 Temmuz'da gerçekleşmiştir. Bir sonraki yıl (2019) ise; Tane Tutumu (EL 27) 15 Haziran'da, İri Koruk (EL 31) 05 Temmuz'da ve Ben Düşme (EL 35) 03 Ağustos tarihinde kaydedilmiştir.

Tekirdağ'da 2018 ve 2019 yılları ortalama sıcaklığı $15.57^{\circ} \mathrm{C}$ ve ortalama oransal nem değeri \%73.38 olarak kaydedilmiştir. Vejetasyon döneminde ortalama güneşlenme süresi ise 1449.85 saattir. Yıllık toplam yağış miktarlarının 2018 yılında 675.00 mm ve 2019 yılında $334.60 \mathrm{~mm}$ olduğu tespit edilmiştir. 2018 yılı yağışının uzun yıllar yağış ortalamasının (589.10 mm) $85.90 \mathrm{~mm}$ üzerinde; ancak 2019 yılının ise $340.4 \mathrm{~mm}$ altında olduğu hesaplanmıştır. Buradan 2019 yılının kurak geçtiği görülmüştür.

\section{Salkım eni $(\mathrm{cm})$}

Farklı dönemlerde yapılan yaprak alma ve uç alma uygulamalarının salkım eni üzerine etkilerini ortaya koymak amacıyla 2018 ve 2019 yıllarının birleştirmesi yapılarak Çizelge 1'de sunulmuştur. Yıl Ana Etkisi (YAET), Dönem Ana Etkisi (DAET), Uygulama Ana Etkisi (UAET)'nin istatistiki olarak LSD \%5 seviyesinde önemli olduğu görülmüştür. Ancak UAET x DAET interaksiyonu önemli bulunmamıştır. YAET'ne göre 2018 yılı $(15.43 \mathrm{~cm})$ birinci önem grubunda yer almıştır. Dönem olarak TT dönemi $(15.40 \mathrm{~cm})$ ve uygulama olarak da YA-UA $(16.59 \mathrm{~cm})$ uygulamasının salkım enini artırdığı ortaya çıkmıştır. Salkım eni değerleri incelendiğinde 2018-2019 yılında $12.00-25.83 \mathrm{~cm}$ arasında değiştiği belirlenmiştir. 
Farklı Zamanlarda Yapılan Yaprak Alma ve Uç Alma Uygulamalarının Üzümde

Salkım Özellikleri Üzerine Etkilerinin Belirlenmesi

Çizelge 2. Farklı dönemlerde yapılan yaprak alma ve uç alma uygulamalarının salkım boyu üzerine 2018 ve 2019 yıllarındaki etkileri

\begin{tabular}{|c|c|c|c|c|c|c|c|c|}
\hline \multirow[t]{3}{*}{ Dönemler } & \multirow[t]{2}{*}{ Yıllar } & \multicolumn{3}{|c|}{ Uygulamalar } & \multicolumn{3}{|c|}{ Ana Etkiler } & \\
\hline & & Kontrol & YAY-UA & YA-UAY & YA-UA & DAET & YAET & \\
\hline & 2018 & 27.67 & 26.50 & 26.50 & 17.33 & & & \\
\hline \multirow[t]{3}{*}{$\mathrm{TT}$} & 2019 & 26.00 & 26.00 & 27.50 & 22.00 & 24.94 & & \\
\hline & YIl Ort. & 26.84 & 26.25 & 27.00 & 19.67 & & & \\
\hline & 2018 & 25.33 & 27.00 & 23.17 & 26.50 & & $24.83 B$ & $26.12 A$ \\
\hline \multirow[t]{3}{*}{ İK } & 2019 & 25.03 & 25.33 & 26.57 & 28.67 & 25.95 & (2018) & (2019) \\
\hline & YIl Ort. & 25.18 & 26.17 & 24.87 & 27.59 & & & \\
\hline & 2018 & 26.33 & 23.67 & 22.83 & 25.17 & & & \\
\hline \multirow[t]{2}{*}{$B D$} & 2019 & 25.33 & 27.43 & 28.40 & 25.20 & 25.54 & & \\
\hline & Yil Ort. & 25.83 & 25.55 & 25.62 & 25.19 & & & \\
\hline UAET & & 25.95 & 25.99 & 25.83 & 24.14 & & & \\
\hline
\end{tabular}

[TT: Tane Tutumu, İ: İri Koruk, BD: Ben Düşme; YAY-UA: Yaprak Alma Yok_Uç Alma, YA-UAY: Yaprak Alma-Uç Alma Yok, YA-UA: Yaprak Alma-Uç Alma; DAET: Dönem Ana Etkisi, YAET: Yıl Ana Etkisi, UAET: Uygulama Ana Etkisi]

YAET LSD \%5=1.186 (Büyük harfle ve italik yazılmıştır)

Çizelge 3. Farklı dönemlerde yapılan yaprak alma ve uç alma uygulamalarının salkım ağırı̆̆ı üzerine 2018 ve 2019 yıllarındaki etkileri

\begin{tabular}{|c|c|c|c|c|c|c|c|c|}
\hline \multirow[t]{2}{*}{ Dönemler } & \multirow[t]{2}{*}{ Yillar } & \multicolumn{4}{|c|}{ Uygulamalar } & \multicolumn{3}{|c|}{ Ana Etkiler } \\
\hline & & Kontrol & YAY-UA & YA-UAY & YA-UA & DAET & YAET & \\
\hline & 2018 & 487.85 & 422.11 & 368.37 & 454.05 & & & \\
\hline \multirow[t]{3}{*}{ TT } & 2019 & 493.64 & 558.62 & 448.89 & 445.24 & 459.85 & & \\
\hline & Yıl Ort. & 490.75 & 490.37 & 408.63 & 449.65 & & & \\
\hline & 2018 & 585.60 & 386.36 & 464.85 & 532.18 & & & \\
\hline \multirow[t]{3}{*}{ İk } & 2019 & 447.12 & 460.25 & 458.76 & 720.14 & 506.91 & 484.48 & 506.81 \\
\hline & Yll Ort. & 516.36 & 423.31 & 461.81 & 626.16 & & & \\
\hline & 2018 & 571.37 & 522.12 & 451.07 & 567.85 & & & \\
\hline \multirow[t]{2}{*}{$B D$} & 2019 & 547.10 & 505.15 & 515.62 & 481.88 & 520.27 & & \\
\hline & Yıl Ort. & 559.24 & 513.64 & 483.35 & 524.87 & & & \\
\hline UAET & & 522.11 & 475.77 & 451.26 & 533.56 & & & \\
\hline
\end{tabular}

[TT: Tane Tutumu, IK: İri Koruk, BD: Ben Düşme; YAY-UA: Yaprak Alma Yok_Uç Alma, YA-UAY: Yaprak Alma-Uç Alma Yok, YA-UA: Yaprak Alma-Uç Alma; DAET: Dönem Ana Etkisi, YAET: Yıl Ana Etkisi, UAET: Uygulama Ana Etkisi] Ö.D.

Çizelge 4. Farklı dönemlerde yapılan yaprak alma ve uç alma uygulamalarının salkım hacmi üzerine 2018 ve 2019 yıllarındaki etkileri

\begin{tabular}{|c|c|c|c|c|c|c|c|c|}
\hline \multirow[t]{2}{*}{ Dönemler } & \multirow[t]{2}{*}{ Yillar } & \multicolumn{4}{|c|}{ Uygulamalar } & \multicolumn{3}{|c|}{ Ana Etkiler } \\
\hline & & Kontrol & YAY-UA & YA-UAY & YA-UA & DAET & YAET & \\
\hline & 2018 & 344.70 & 381.49 & 425.76 & 433.57 & & & \\
\hline \multirow[t]{3}{*}{ TT } & 2019 & 278.50 & 315.16 & 253.25 & 251.19 & 335.45 & & \\
\hline & Yıl Ort. & 311.60 & 348.33 & 339.51 & 342.38 & & & \\
\hline & 2018 & 434.55 & 416.71 & 334.12 & 431.33 & & & \\
\hline \multirow[t]{3}{*}{ İK } & 2019 & 252.25 & 259.66 & 258.82 & 406.47 & 349.24 & $\begin{array}{l}410.09 A \\
(2018)\end{array}$ & 200.91 D \\
\hline & Yıl Ort. & 343.40 & 338.19 & 296.47 & 418.90 & & & \\
\hline & 2018 & 470.66 & 434.29 & 411.32 & 469.84 & & & \\
\hline \multirow[t]{2}{*}{ BD } & 2019 & 308.66 & 284.99 & 290.89 & 271,86 & 367.81 & & \\
\hline & Yıl Ort. & 389.66 & 359.64 & 351.11 & 370,85 & & & \\
\hline \multicolumn{2}{|l|}{ UAET } & 348,22 & 348.72 & 329.03 & 377.38 & & & \\
\hline \multicolumn{9}{|c|}{$\begin{array}{l}\text { [TT: Tane Tutumu, IK: İri Koruk, BD: Ben Düşme; YAY-UA: Yaprak Alma Yok_Uç Alma, YA-UAY: Yaprak Alma-Uç Alma Yok, YA-UA: Yaprak } \\
\text { Alma-Uç Alma; DAET: Dönem Ana Etkisi, YAET: Yıl Ana Etkisi, UAET: Uygulama Ana Etkisi] } \\
\text { YAET LSD \%5=45.26 (Büyük harf ve italik yazılmıştır) }\end{array}$} \\
\hline
\end{tabular}


Salkımdaki tane sayısı (adet)

Salkımdaki tane sayısının yıl birleştirme değerleri incelendiğinde YAET, UAET, DAET ve UAET $x$ DAET interaksiyonlarının istatistiki olarak önemli olmadığı kaydedilmiştir (Çizelge 5).

Salkımdaki tane sayısının UAET bakımından rakamsal olarak yüksek değerlere YA-UAY uygulaması (80.47 adet) ve YAET'ne göre 2018 yılı ortalamasında erişildiği tespit edilmiştir.

DAET incelendiğinde BD döneminde (80.96 adet) salkımdaki tane sayısı yüksektir. UAET x DAET interaksiyonu açısından YAY-UA x TT kombinasyonunun (87.33 adet) yüksek değeri aldığı saptanmıştır.

Kotseridis ve ark. (2012), Merlot ve Sangiovese üzüm çeşitlerinde yaprak alma uygulaması ile salkımdaki tane sayısının azaldığını bulmuşlardır. Başka bir araştırmada Merlot üzüm çeşidinde yapılan uç alma uygulaması ile salkımdaki tane sayısının arttığı belirlenmiştir (Korkutal ve ark., 2018).

Yapılan araştırmada rakamsal olarak değerler birbirine yakın olup; YA-UAY ve YAY-UA uygulamaları ile yüksek tane sayısı değerine ulaşılmıştır. Diğer araştırmacıların bulgularıyla karşılaştırıldığında salkımdaki tane sayısını artırmak için Yaprak Alma veya Uç Alma uygulamalarından yalnızca birinin yapılması gerektiği sonucuna varılmıştır.

\section{Salkım sıklığı}

Salkım sıklığı bakımından UAET, DAET ve bunların interaksiyonları incelenmiş, 2018 ve 2019 yılı verilerine göre istatistiki olarak önemli bulunmamıştır (Çizelge 6).

Farklı sofralık üzüm çeşitlerindeki salkım sıklığının genellikle yüksek düzeydeki yapılan koltuk alma uygulamaları ile azalış gösterdiği Türker ve Dardeniz (2014) tarafından bulunmuştur. Benzer şekilde Kaya (2019), Karaerik üzüm çeşidinde yaptığı yaprak alma ile kontrole kıyasla salkım sıklığının azaldığını görmüştür. Öte yandan yapılan yaprak alma uygulamaları sonucunda Cabernet Sauvignon ve
Sangiovese üzüm çeşitlerinde salkım sıklığı artmış; Merlot üzüm çeşidinde yaprak alma şiddetine bağlı olarak salkım sıklığının azaldığı görülmüştür (Kotseridis ve ark., 2012). Araştırmada TT döneminde (0.56) yapılan uygulamaların salkım sıklığını diğer dönemlere (0.66) göre nispeten azalttığı tespit edilmiştir. YA-UAY uygulamasının (0.59) düşük salkım sıklığı değeri veren uygulama olduğu saptanmış, bu sonucun Kotseridis ve ark. (2012)'nın bulgusuyla paralel olduğu belirlenmiştir.

\section{Omca başına verim (kg/omca)}

Asma başına verim üzerine YAET istatistiki olarak LSD \%5 seviyesinde önemli; UAET, DAET ve UAET $x$ DAET interaksiyonlarının ise istatistiki olarak önemli etkide bulunmadığı görülmüştür (Çizelge 7). Yaprak Alma ve Uç Alma uygulamaları sonucunda; YAET'ne bakıldığında 2018 yılı birinci önem grubunda yer almış; UAET bakımından rakamsal olarak YA-UA (14.90 kg/omca) uygulamasının diğer uygulamalardan yüksek değere sahip olduğu belirlenmiştir. DAET açısından; ík döneminde omca başına verimin $14.37 \mathrm{~kg} /$ omca değerinde olduğu görülmüştür. YAUA x IK kombinasyonundan 16.15 kg/omca değerinin elde edildiği bulunmuştur. Cardinal ve Amasya Beyazı sofralık üzüm çeşitlerinde yüksek düzeydeki koltuk alma uygulaması ile ortalama verimde önemli bir değişiklik saptanamamıştır. Bununla birlikte, yüksek düzeydeki koltuk alma uygulamasının Yalova İncisi, Yalova Çekirdeksizi, Ata Sarısı ve Kozak Beyazı çeşitlerinde ise ortalama verimde azalmalara neden olduğu görülmüştür (Türker ve Dardeniz, 2014). Kaya (2019), Karaerik üzüm çeşidinde çiçeklenme öncesi, tam çiçeklenme ve tane tutumunda yaptığı yaprak alma ile kontrole kıyasla verim azaldığını görmüştür. Bu araştırmada Yaprak Alma ve Uç Alma uygulamasının birlikte yapılmasının verimi olumlu yönde etkilediği ortaya çıkmıştır. Diğer çalışmalar incelendiğinde yaprak alma ve uç alma uygulamalarında; çeşit ve uygulamaların gerçekleşme döneminin önemli olduğu sonucuna ulaşılmıştır.

Çizelge 5. Farklı dönemlerde yapılan yaprak alma ve uç alma uygulamalarının salkımdaki tane sayısı üzerine 2018 ve 2019 yıllarındaki etkileri

\begin{tabular}{|c|c|c|c|c|c|c|c|c|}
\hline \multirow[t]{2}{*}{ Dönemler } & \multirow[t]{2}{*}{ Yıllar } & \multicolumn{4}{|c|}{ Uygulamalar } & \multicolumn{3}{|c|}{ Ana Etkiler } \\
\hline & & Kontrol & YAY-UA & YA-UAY & YA-UA & DAET & YAET & \\
\hline & 2018 & 74.50 & 74.33 & 78.17 & 87.83 & & & \\
\hline \multirow[t]{3}{*}{$\mathrm{TT}$} & 2019 & 70.00 & 100.33 & 89.00 & 58.00 & 79.02 & & \\
\hline & Yıl Ort. & 72.25 & 87.33 & 83.59 & 72.92 & & & \\
\hline & 2018 & 80.00 & 78.33 & 76.83 & 74.50 & & & \\
\hline \multirow[t]{3}{*}{ ì } & 2019 & 65.00 & 65.00 & 76.00 & 63.00 & 72.33 & $\begin{array}{l}81.04 \\
(2018)\end{array}$ & $\begin{array}{l}13.85 \\
(2019)\end{array}$ \\
\hline & Yll Ort. & 72.50 & 71.67 & 76.42 & 68.75 & & & \\
\hline & 2018 & 85.50 & 78.17 & 88.50 & 95,83 & & & \\
\hline \multirow[t]{2}{*}{ BD } & 2019 & 78.33 & 71.67 & 74.33 & 75,33 & 80.96 & & \\
\hline & Yıl Ort. & 81.92 & 74.92 & 81.42 & 85,58 & & & \\
\hline UAET & & 75,56 & 77.97 & 80.47 & 75.75 & & & \\
\hline
\end{tabular}


Farklı Zamanlarda Yapılan Yaprak Alma ve Uç Alma Uygulamalarının Üzümde

Salkım Özellikleri Üzerine Etkilerinin Belirlenmesi

Çizelge 6. Farklı dönemlerde yapılan yaprak alma ve uç alma uygulamalarının salkım sıklı̆̆ı̈zerine 2018 ve 2019 yıllarındaki etkileri

\begin{tabular}{|c|c|c|c|c|c|c|c|c|}
\hline \multirow[t]{2}{*}{ Dönemler } & \multirow[t]{2}{*}{ Yıllar } & \multicolumn{4}{|c|}{ Uygulamalar } & \multicolumn{3}{|c|}{ Ana Etkiler } \\
\hline & & Kontrol & YAY-UA & YA-UAY & YA-UA & DAET & YAET & \\
\hline & 2018 & 0,59 & 0,64 & 0,68 & 0,53 & & & \\
\hline \multirow[t]{3}{*}{ TT } & 2019 & 0,56 & 0,49 & 0,41 & 0,58 & 0,56 & & \\
\hline & Yll Ort. & 0,58 & 0,57 & 0,55 & 0,56 & & & \\
\hline & 2018 & 0,64 & 0,54 & 0,56 & 0,65 & & & \\
\hline \multirow[t]{3}{*}{ ik } & 2019 & 0,59 & 0,61 & 0,61 & 1,07 & 0,66 & 0,63 & 0,63 \\
\hline & Yll Ort. & 0,62 & 0,58 & 0,59 & 0,86 & & (2018) & \\
\hline & 2018 & 0,72 & 0,77 & 0,61 & 0,59 & & & \\
\hline \multirow[t]{2}{*}{ BD } & 2019 & 0,67 & 0,66 & 0,67 & 0,59 & 0,66 & & \\
\hline & Yll Ort. & 0,70 & 0,72 & 0,64 & 0,59 & & & \\
\hline UAET & & 0,62 & 0,62 & 0,59 & 0,67 & & & \\
\hline
\end{tabular}

[TT: Tane Tutumu, IK: İri Koruk, BD: Ben Düşme; YAY-UA: Yaprak Alma Yok_Uç Alma, YA-UAY: Yaprak Alma-Uç Alma Yok, YA-UA: Yaprak Alma-Uç Alma; DAET: Dönem Ana Etkisi, YAET: Yıl Ana Etkisi, UAET: Uygulama Ana Etkisi]

Ö.D.

Çizelge 7. Farklı dönemlerde yapılan yaprak alma ve uç alma uygulamalarının omca başına verim üzerine 2018 ve 2019 yıllarındaki etkileri

\begin{tabular}{|c|c|c|c|c|c|c|c|c|}
\hline \multirow[t]{2}{*}{ Dönemler } & \multirow[t]{2}{*}{ Yillar } & \multicolumn{4}{|c|}{ Uygulamalar } & \multicolumn{3}{|c|}{ Ana Etkiler } \\
\hline & & Kontrol & YAY-UA & YA-UAY & YA-UA & DAET & YAET & \\
\hline & 2018 & 16.01 & 16.14 & 13.99 & 17.70 & & & \\
\hline \multirow[t]{3}{*}{ TT } & 2019 & 6.11 & 11.17 & 6.19 & 9.09 & 12.05 & & \\
\hline & Yıl Ort. & 11.06 & 13.66 & 10.09 & 13.40 & & & \\
\hline & 2018 & 21.39 & 14.58 & 16.59 & 19.42 & & & \\
\hline \multirow[t]{3}{*}{ İK } & 2019 & 9.06 & 9.10 & 11.96 & 12.88 & 14.37 & $17.31 \mathrm{~A}$ & $9.10 \mathrm{~B}$ \\
\hline & YIl Ort. & 15.23 & 11.84 & 14.28 & 16.15 & & & \\
\hline & 2018 & 18.91 & 17.77 & 14.44 & 20.79 & & & \\
\hline \multirow[t]{2}{*}{$B D$} & 2019 & 10.28 & 10.50 & 10.54 & 9.52 & 14.09 & & \\
\hline & YIl Ort. & 14.60 & 14.14 & 12.49 & 15.16 & & & \\
\hline UAET & & 13,63 & 13.21 & 12.29 & 14.90 & & & \\
\hline
\end{tabular}

[TT: Tane Tutumu, IK: İri Koruk, BD: Ben Düşme; YAY-UA: Yaprak Alma Yok_Uç Alma, YA-UAY: Yaprak Alma-Uç Alma Yok, YA-UA: Yaprak Alma-Uç Alma; DAET: Dönem Ana Etkisi, YAET: Yıl Ana Etkisi, UAET: Uygulama Ana Etkisi]

YAET LSD \%5=2,030 (Büyük harf ve italik yazıımıştır)

Çizelge 8. Farklı dönemlerde yapılan yaprak alma ve uç alma uygulamalarının birinci sınıf salkım oranı üzerine 2018 ve 2019 yıllarındaki etkileri

\begin{tabular}{|c|c|c|c|c|c|c|c|c|}
\hline \multirow[t]{2}{*}{ Dönemler } & \multirow[t]{2}{*}{ Yıllar } & \multicolumn{4}{|c|}{ Uygulamalar } & \multicolumn{3}{|c|}{ Ana Etkiler } \\
\hline & & Kontrol & YAY-UA & YA-UAY & YA-UA & DAET & YAET & \\
\hline & 2018 & 32.50 & 31.33 & 24.67 & 29,83 & & & \\
\hline \multirow[t]{3}{*}{ TT } & 2019 & 73.22 & 72.97 & 78.81 & 75,00 & 52.29 & & \\
\hline & YIl Ort. & 52.86 & 52.15 & 51.74 & 52,42 & & & \\
\hline & 2018 & 35.67 & 27.50 & 31.17 & 32,17 & & & \\
\hline \multirow[t]{3}{*}{ IK } & 2019 & 70.37 & 69.30 & 72.06 & 75,69 & 51.74 & $\begin{array}{l}29.98 B \\
(2018)\end{array}$ & (2019) \\
\hline & Yıl Ort. & 53.02 & 48.40 & 51.62 & 53,93 & & & \\
\hline & 2018 & 29.00 & 29.33 & 24.67 & 32,00 & & & \\
\hline \multirow[t]{2}{*}{$B D$} & 2019 & 65.13 & 71.27 & 69.83 & 76,58 & 49.72 & & \\
\hline & YIl Ort. & 47.07 & 50.30 & 47.25 & 54,29 & & & \\
\hline \multicolumn{2}{|l|}{ UAET } & 50.98 & 50.28 & 50.19 & 53.55 & & & \\
\hline \multicolumn{9}{|c|}{$\begin{array}{l}\text { [TT: Tane Tutumu, IK: İri Koruk, BD: Ben Düşme; YAY-UA: Yaprak Alma Yok_Uç Alma, YA-UAY: Yaprak Alma-Uç Alma Yok, YA-UA: Yaprak } \\
\text { Alma-Uç Alma; DAET: Dönem Ana Etkisi, YAET: Yıl Ana Etkisi, UAET: Uygulama Ana Etkisi] } \\
\text { YAET LSD \%5=2.589 (Büyük harf ve italik yazılmıştır) }\end{array}$} \\
\hline
\end{tabular}




\section{Birinci Sınıf Salkım Oranı (\%)}

Birinci sınıf salkım oranı üzerine YAET istatistiki olarak LSD \%5 seviyesinde önemlidir. UAET, DAET ve UAET $x$ DAET interaksiyonlarının ise LSD \%5 seviyesinde istatistiki olarak önemli olmadığı Çizelge 8'de görülmektedir.

Birinci sınıf salkım oranı üzerine YAET incelendiğinde; farklı dönemlerde yapılan yaprak ve uç alma uygulamaları sonucunda 2019 yılı (\%72.51) birinci önem grubunda yer almıştır. UAET için yüksek değer YA-UA uygulamasıyla (\%53.55) alınmış olup; DAET'ne göre TT döneminin (\%52.29) yüksek etkiye sahip olduğu anlaşılmıştır.

UAET $x$ DAET interaksiyonu bakımından YA-UA $x$ BD (\%54.29) kombinasyonunun birinci sınıf salkım oranı üzerine etkili olduğu tespit edilmiştir. Sofralık üzüm çeşitlerinde birinci sınıf salkım oranı önemli olduğundan; çalışma sonucunda YA-UA uygulamasının bu oranı her iki yılda da oransal olarak artırdığı ortaya çıkmıştır.

\section{íkinci Sınıf Salkım Oranı (\%)}

İkinci sınıf salkım oranı üzerine YAET istatistiki olarak LSD \%5 seviyesinde önemli bulunmuştur. UAET, DAET ve UAET $x$ DAET interaksiyonlarının ise istatistiki olarak önemli olmadığı görülmüş olup sonuçlar Çizelge 9'de verilmiştir.

UAET bakımından rakamsal olarak YA-UAY (\%49.80) uygulaması; DAET'nin ise BD döneminde (\%50.27) artış göstermiştir.

YAET’ne göre 2018 yılının birinci önem grubunda yer aldığı belirlenmiştir. İkinci sınıf salkım oranı 2018 yılında artmıştır. Interaksiyonlar için Kontrol x BD (\%52.94) kombinasyonu ikinci sınıf salkım oranını tetiklemiştir.

Çizelge 9. Farklı dönemlerde yapılan yaprak alma ve uç alma uygulamalarının ikinci sınıf salkım oranı üzerine 2018 ve 2019 yıllarındaki etkileri

\begin{tabular}{|c|c|c|c|c|c|c|c|c|}
\hline \multirow[t]{2}{*}{ Dönemler } & \multirow[t]{2}{*}{ Yıllar } & \multicolumn{4}{|c|}{ Uygulamalar } & \multicolumn{3}{|c|}{ Ana Etkiler } \\
\hline & & Kontrol & YAY-UA & YA-UAY & YA-UA & DAET & YAET & \\
\hline & 2018 & 67.50 & 68.67 & 75.33 & 70.17 & & & \\
\hline \multirow[t]{3}{*}{ TT } & 2019 & 26.78 & 27.03 & 21.19 & 25.00 & 47.70 & & \\
\hline & YIl Ort. & 47.14 & 47.85 & 48.26 & 47.59 & & & \\
\hline & 2018 & 64.33 & 72.50 & 68.83 & 67.83 & & & \\
\hline \multirow[t]{3}{*}{ İ } & 2019 & 29.63 & 30.70 & 27.94 & 24.31 & 48.26 & 70.01 A & $27.48 B$ \\
\hline & Yıl Ort. & 46.98 & 51.60 & 48.39 & 46.07 & & (2018) & \\
\hline & 2018 & 71.00 & 70.67 & 75.33 & 68.00 & & & \\
\hline \multirow[t]{2}{*}{ BD } & 2019 & 34.87 & 28.73 & 30.17 & 23.42 & 50.27 & & \\
\hline & YIl Ort. & 52.94 & 49.70 & 52.75 & 45.71 & & & \\
\hline UAET & & 49,02 & 49.72 & 49.80 & 46.46 & & & \\
\hline
\end{tabular}

[TT: Tane Tutumu, IK: İri Koruk, BD: Ben Düşme; YAY-UA: Yaprak Alma Yok_Uç Alma, YA-UAY: Yaprak Alma-Uç Alma Yok, YA-UA: Yaprak Alma-Uç Alma; DAET: Dönem Ana Etkisi, YAET: Yıl Ana Etkisi, UAET: Uygulama Ana Etkisi] YAET LSD \%5=2.589 (Büyük harf ve italik yazılmıștır)

\section{SONUÇ}

Bu çalışmada; Michele Palieri üzüm çeşidine vejetasyon periyodu boyunca Tane Tutumu, İri Koruk ve Ben Düşme dönemlerinde yaprak ve uç alma işlemleri uygulanmıştır; bu uygulamaların ve uygulama dönemlerinin salkım ve verim özellikleri üzerine etkileri incelenmiştir.

Farklı dönem ve farklı yaprak alma ve uç alma uygulamalarının salkım özellikleri üzerine istatistiki açıdan önemli bir etkisinin olmadığı görülmüştür. Sadece TT döneminde YA-UA uygulamasının salkım enini önemli derecede artırdığı tespit edilmiştir. Salkım boyu için de belirlenen değerlerin rakamsal olarak birbirine yakın olduğu ve uygulamaların istatistiki olarak önemli bir etkisinin olmadığı bulunmuştur. Salkımdaki tane sayısını artırmak için YA-UAY ve YAY-UA uygulamalarının etkili olduğu tespit edilmiştir. Salkım ağırığı, salkım hacmi ve salkım sıklığı kriterleri için YA-UA uygulamasının yükseltici etkisi olduğu kaydedilmiştir. Sonuç olarak; YA-UA uygulamasının genel olarak salkım özellikleri için etkili olduğu ortaya çıkmıştır. Verim özellikleri incelendiğinde, IK döneminde YA-UA uygulamasının omca başına verimi nispeten artırdığı sonucuna ulaşılmıştır. Birinci sınıf salkım oranının İK döneminde yapılan YA-UA uygulamasıyla arttığı görülmüş olup; bununla beraber ikinci sınıf salkım oranının ise BD döneminde YA-UAY uygulamasıyla arttığı ortaya çıkmıştır. Her iki sınıf salkım oranı değerleri incelendiğinde birinci sınıf salkım oranı 2019 yılında en yüksek, ikinci sınıf salkım oranı 2018 yılında en yüksek bulunmuştur. Bu sonuçlardan hareketle yapılan uygulamaların oransal olarak birinci sınıf salkım oranını artırıcı, ikinci sınıf salkım oranını azaltıcı etkide olduğu belirlenmiştir.

Sonuç olarak; salkım özellikleri açısından yağışlı sezonlarda Ben Düşme döneminde; kurak sezonlarda ise İri Koruk döneminde yapılacak olan YA-UA uygulamasının bağda kaliteyi artırmasının muhtemel olduğu gözlenmiştir. Tekirdağ ilinde, yüksek kollu " $T$ " terbiye şeklindeki Michele Palieri üzüm çeşidinde, yüksek kalitede üzüm elde edebilmesi için; bağcıların iklim özelliklerini takip edip, yapılacak uygulamaları ve uygulama dönemlerini asmanın özellikleriyle birlikte değerlendirmeleri gerektiği görülmüştür. Verimliliği artırmak için İri Koruk döneminde YA-UA uygulaması tavsiye edilebilir bulunmuştur. 


\section{KAYNAKLAR}

Alessandrini M, Battista F, Panighel A, Flamini R, Tomasi D (2018) Effect of Pre-Bloom Leaf Removal on Grape Aroma Composition and Wine Sensory Profile of Semillon Cultivar. Journal of the Science of Food and Agriculture 98 (5): 1674-1684.

Bahar E, Öner H (2015) Cabernet Sauvignon Üzüm Çeşidinde Farklı Kültürel İşlemlerin Verim ve Kalite Özellikleri Üzerine Etkileri. Journal of Atatürk Central Horticultural Research Institute 45 (Özel Sayı): 591 598.

Bubola M, Lukic I, Radeka S, Sivilotti P, Grozic K, Vanzo A, Lisjak K (2019) Enhancement of Istrian Malvasia Wine Aroma and Hydroxycinnamate Composition by Hand and Mechanical Leaf Removal. Journal of the Science of Food and Agriculture 99 (2): 904-914.

Çelik H (2017) Bağlarda Taç Yönetimi-Yaz Budamaları. TÜRKTOB Dergisi 22: 34-43.

Dardeniz A, Gündoğdu A, Mehmet Akçal A, Sarıyer T, Atik F, Harput N (2018) Yalova Çekirdeksizi Üzüm Çeşidinin Yazlık Sürgünlerinde Farklı Tepe Alma Uygulamalarının Yılık Dal ile Üzüm Verim ve Kalitesine Etkileri. Çanakkale Onsekizmart Üniversitesi Ziraat Fakültesi Dergisi 6 (1): 51-59.

Hernandes JL, Junior MJP (2018) Yield and Grape Must Quality of the IAC 138-22 Máximo Submitted to Canopy Management. Revista Ceres 65 (6): 527-533.

Kaya O (2019) Effect of Manual Leaf Removal and its Timing on Yield, the Presence of Lateral Shoots and Cluster Characteristics with the Grape Variety Karaerik. Mitteilungen Klosterneuburg Rebe und Wein Obstbau und Früchteverwertung 69(2): 83-92.

Kılıç MS (2019) Red Globe Üzüm Çeşidinde Bazı Yaz Budama Uygulamalarının Meyve Verim ve Kalitesi Üzerine Etkileri. Yüksek Lisans Tezi Isparta Uygulamalı Bilimler Üniversitesi Fen Bilimleri Enstitüsü.

Korkutal i, Bahar E, Bayram S (2017) Farklı Toprak İşleme ve Yaprak Alma Uygulamalarının Syrah Üzüm Çeşidinde Su Stresi, Salkım ve Tane Özellikleri Üzerine Etkileri. Ege Üniversitesi Ziraat Fakültesi Dergisi 54 (4): 397407.

Korkutal i, Bahar E, Kaygusuz G (2018) Farklı Uç Alma Dönemleri ve Farklı Dozlarda Azot Uygulamalarının Merlot (Vitis vinifera L.) Üzüm Çeşidinde Salkım ve Tane Özellikleri Üzerine Etkilerinin Belirlenmesi. Mediterranean Agricultural Sciences 31 (3): 199-207.

Köse B, Çelik H, Çelik D (2018) Determination of the Effects of Less and Excessive Leaf Removal on Cluster Characteristics in Trakya Ilkeren Grape Variety. Proceedings of the IX. International Scientific Agriculture Symposium AGROSYM, October 04-07, Jahorina, Bosnia and Herzegovina. pp. 775-781.

Kotseridis Y, Georgiadou A, Tikos P, Kallithraka S, Koundouras S (2012) Effects of Severity of Post-
Flowering Leaf Removal on Berry Growth and Composition of Three Red Vitis vinifera L. Cultivars Grown Under Semiarid Conditions. Journal of Agricultural and Food Chemistry 60 (23): 6000-6010.

Lorenz DH, Eichhorn KW, Bleiholder H, Klose R, Meier U, Weber E (1995) Phenological Growth Stages of the Grapevine (Vitis vinifera L. ssp. vinifera) Codes and Descriptions According to the Extended BBCH Scale. Australian Journal of Grape and Wine Research 1: 100-110.

Mosetti D, Herrera JC, Sabbatini P, Green A, Alberti G, Peterlunger E, Lisjak K, Castellarin SD (2016) Impact of Leaf Removal After Berry Set on Fruit Composition and Bunch Rot in Sauvignon blanc. Vitis 55: 57-64.

Mota RV, Souza CRC, Silva PC, Freitas GF, Shiga TM, Purgatto E, Lajolo FM, Regina MA (2010) Biochemical and Agronomical Responses of Grapevines to Alteration of Source-Sink Ratio by Cluster Thinning and Shoot Trimming. Bragantia 69 (1): 17-25.

OIV (2009) $2^{\text {nd }}$ Edition of the OIV Descriptor List for Grape Varieties and Vitis Species. http://www.oiv.int/public/medias/2274/code-2eedition-finale.pdf (Erişim tarihi: 09.12.2020).

TMM (2019) Tekirdağ Meteoroloji Müdürlüğü 2018 ve 2019 yılı iklim verileri kayıtları.

Teker T (2017). Bağcılıkta Yeşil (Yaz) Budaması Uygulamaları. Manisa Bağcılık Araştırma Enstitüsü. 34s.

Türker L, Dardeniz A (2014) Sofralık Üzüm Çeşitlerinde Farklı Düzeylerdeki Koltuk Alma Uygulamalarının Verim ve Kalite Özellikleri Üzerindeki Etkileri. ÇOMÜ Ziraat Fakültesi Dergisi 2 (2): 73-82.

Vivin P, Castelán-Estrada M (2002) A Source/Sink Model to Simulate Seasonal Allocation of Carbon in Grapevine. Acta Horticulturae 584.

Vogel AR, White RS, MacAllister C, Hickey CC (2020) Fruit Zone Leaf Removal Timing and Extent Alters Bunch Rot, Primary Fruit Composition, and Crop Yield in Georgia-Grown Chardonnay (Vitis vinifera L.). HortScience 55 (10): 1654-1661.

Würz DA, Allebrandt R, Marcon Filho JL, Bem BPD, Brighenti $A F$, Rufato L, Kretzschmar AA (2018) Leaf Removal Timing and its Influence on Wine Grape Performance Sauvignon Blanc in High Altitude Region. Revista de Ciencias Agroveterinarias 17 (1): 91-99.

Yüksel i, Ateş F (2020) Bağcılıkta Budama ve Terbiye Sistemleri.

https://arastirma.tarimorman.gov.tr/manisabagcilik/b elgeler/genelbagcilik/baglarda\%20budama\%20ve\%20 terbiye\%20sistemleri\%20ismail\%20yuksel(1).pdf (Erişim tarihi: 01.12.2020). 